\title{
Sistema de impermeabilização: Método de aplicação em fundações
}

Visi Paulo Lumuangiki

Engenharia Civil pelo CEFET-RJ, Rio de Janeiro, RJ, Brasil ra.brandao.gaspar@gmail.com

Clézio Thadeu de Souza Dutra Doutor em sustentabilidade de obras pela Universidade Federal Fluminense (UFF) Professor do Departamento de Engenharia Civil CEFET-RJ, Rio de Janeiro, RJ, Brasil clezio@coneeng.com.br

Vinicius Araújo de Souza Dutra Mestrando em gestão em construção civil - Universidade Federal Fluminense (UFF) viniciusdutra@poli.ufrj.br

\section{RESUMO}

O trabalho visa detalhar os possíveis impermeabilizantes para áreas de subsolos como paredes diafragmas. Também são referidas as fundações passiveis de serem impermeabilizadas: sapatas (isoladas, corridas ou vigas), estacas (topo ou maciço de encabeçamento), desta forma, os projetos arquitetônicos são concebidos sempre visando ao máximo o aproveitamento destas áreas. Os pavimentos inferiores são bastante afetados pela água. Pois estão sujeitos a maiores concentrações de água da chuva e influência do lençol freático. Apresentando materiais e métodos mais indicados para esta situação, assim como os pontos que merecem um cuidado especial. São referidas também as anomalias correntes em fundações e nos materiais que as protegem. É possível ainda abordar técnicas de reabilitação, focando-se fundamentalmente em radier. Serão detalhadas todas as situações das obras e soluções escolhidas em cada caso.

Palavras-chave: Impermeabilização. Pressão Hidrostática. Fundações. Paredes diafragmas.

\section{Waterproofing system: Application method in foundations}

\begin{abstract}
The Test aims to detail possible waterproofing for underground areas such as diaphragm walls. Also mentioned are foundations that can be waterproofed: shoes (insulated, races or beams), stakes (top or mass of header), in this way, architectural designs are always designed to maximize the use of these areas. The lower floors are heavily affected by water. They are subject to higher concentrations of Rainwater and influence of the water table. By presenting materials and methods that are most suitable for that situation, as well as the points that deserve special care. Are also mentioned the current anomalies in foundations and the materials that protect them. It is also possible to approach rehabilitation techniques, focusing fundamentally on general deformations. It will detail all the situations of the works and solutions chosen in each case.
\end{abstract}

Key Words: Waterproofing. Hydrostatic Pressure. Foundations. Diaphragm Walls. 


\section{INTRODUÇÃO}

Quando se trata de proteger uma construção a técnica de impermeabilização é uma das mais recorrentes e utilizadas. A umidade sempre foi uma preocupação para o homem, desde o tempo em que habitava nas cavernas, percebeu que a umidade começava no solo e penetrava pelas paredes, o que tornava a vida dentro delas precárias. Desde muito tempo procuram-se soluções a fim de proteger a vida útil das construções. (RL- Impermeabilização 2014).

Os primeiros materiais utilizados pelo homem em impermeabilização foram betuminosos, ou seja, os asfaltos e alcatrões, produtos tradicionais usados nos banhos romanos e proteção das estacas de madeira na antiguidade. Os romanos impermeabilizavam estradas com betume como esforço da sub-base e subleito.

A primeira utilização dos materiais betuminosos em coberturas de forma semelhante a que conhecemos atualmente foi em 1790, na Suécia, em tábuas revestidas com papel e impermeabilizadas com alcatrão. Em 1845 começaram a serem utilizados nos estados unido feltros impregnados de alcatrão nas coberturas, até que 1894 que foi desenvolvido asfalto oxidado.

O sistema de impermeabilização de coberturas mais antigo é o denominado "multimembrana asfáltica", ou "feltro asfáltico e asfalto", que consiste na aplicação de diversa camada de asfalto oxidado, a quente, este sistema é utilizado em toda parte do mundo.

Com o grande desenvolvimento da indústria dos polímeros sintéticos, a partir do início do séc. XIX surgiram novos materiais, cujas características de impermeabilidade, elasticidade, extensibilidade, etc., possibilitaram o desenvolvimento de sistemas de impermeabilização de desempenho comparável ao do feltro asfáltico e asfalto, apresentando em geral, maior facilidade de execução. Desta forma diversos sistemas de impermeabilização, sejam moldados no local (como os tradicionais sistemas asfálticos), ou pré-fabricados. É o caso, por exemplo, dos sistemas à base de elastômeros sintéticos (sistema neoprene e hypalon e mantas de butil), utilizados desde a década de 30, e das mantas de PVC. Vem havendo, também um grande desenvolvimento do uso de mantas asfálticas pré-fabricadas, bem como o uso, em sistemas moldados no local, de diversos outros polímeros e de asfaltos modificados com polímeros. (RL-Impermeabilização 2014).

A necessidade de novos materiais impermeabilizantes surgiu como forma de solucionar problemas citados, nomeadamente a utilização de novas membranas de impermeabilização, com o intuito de permitir uma estanqueidade à água e, consequentemente, prolongar a vida útil dos elementos enterrados. (Mendes, 2011). 
Mendes (2011), ainda ressalta que as primeiras membranas surgiram na Europa Central, entre a década de 60 e 70, permitindo maior durabilidade e economia nas novas soluções construtivas. Esta descoberta veio para facilitar a construção em profundidades, protegendo os elementos construtivos.

No Brasil, a impermeabilização ganhou especial impulso para a sua normalização com as primeiras obras de metrô na cidade de São Paulo, que teve início em 1968. A partir de então, iniciaram-se as reuniões para criar as primeiras normas brasileiras de impermeabilização, na ABNT - Associação Brasileira de Normas Técnicas.

A primeira Norma Brasileira de Impermeabilização teve a publicação em 1975, mesmo ano da fundação de $|\mathrm{B}|$ - Instituto Brasileiro de Impermeabilização, instituto responsável pela disseminação da importância da impermeabilização na construção, que se prossegue até os dias de hoje.

De acordo com Mendes (2011), em Portugal, o IPQ membro do European Commttee for Standardization - CEN, através de Comissões Técnicas de Normalização - CT ou de Organização de Normalização Setorial - NOS, sendo da responsabilidade destes a elaboração da versão portuguesa das várias Normas Europeias. São entidades que regulam a utilização dos produtos aplicados na indústria da construção civil.

O objetivo principal deste trabalho compreendeu estudos técnicos de sistemas de impermeabilização mais adequados, independente dos tipos de fundações e subsolos a serem impermeabilizados.

Colocando-se em evidência os sistemas comuns mais utilizados na Europa e em outros países, algumas novas tecnologias implementadas atualmente no mercado com mais objetivos, deuse pela observação da importância da impermeabilização pouco explicativo ou, mais utilizados nas escolhas dos sistemas ideais, de acordo com as etapas de uma obra.

\section{IMPORTÂNCIA DA IMPERMEABILIZAÇÃO}

A importância da impermeabilização, além de permitir habitabilidade da construção civil, é também no objetivo de proteger a edificação de inúmeros problemas patológicos que poderão surgir com a infiltração de água, integradas à atmosfera, oxigênio e outros componentes agressivos da atmosfera (gases poluentes, chuva ácida, ozônio), já que uma grande quantidade de materiais da construção civil sofre um processo de deteorização e degradação, quando em presença dos meios agressivos da atmosfera. (RIPPER,1995). 
As principais funções de impermeabilização são:

- Aumentar a durabilidade dos edifícios;

- Impedir a passagem de água que é um dos líquidos que contribui para a corrosão das armaduras do concreto;

- Proteger as superfícies de umidade, manchas, fungos, etc;

- Garantir ambientes salubres.

A figura 1 apresenta a importância das funções que impermeabilização tem no processo construtivo.

Figura 1 - Processo de impermeabilização
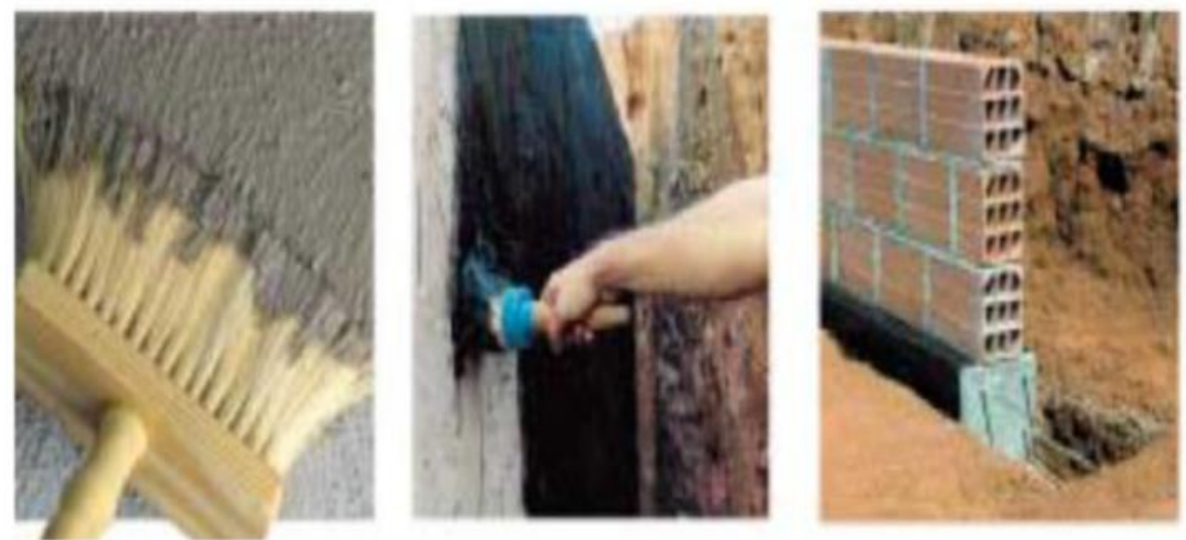

Fonte: (Manual técnico. Otto Baumgart ind. e Com. S.A., 2010).

\section{SISTEMA DE IMPERMEABILIZAÇÃO DE FUNDAÇÕES}

O sistema de impermeabilização do subsolo tem uma grande importância, sendo necessário e imprescindível para um edifício em qualquer centro urbano ou industrial, seja para atender a posturas de código de obras, as vagas de garagem, viabilizar comercialmente um empreendimento, permitir armazenamento de produtos e operação de equipamentos.

Atualmente o espaço destinado ao subsolo é de extrema importância para edifícios residenciais ou comerciais. Ele permite que seja transformado em objeto de ganho de espaço, o que significa construção de vagas de garagens, viabilizando comercialmente o empreendimento. (Lonzetti, 2010).

O sistema de impermeabilização adotado deve atender as exigências de desempenho, conforme citado na norma brasileira NBR 9575:2010.

- Resistir as cargas estáticas e de igual maneira dinâmicas; 
- Resistir aos efeitos do movimento de dilatação e retração do substrato e revestimento, ocasionados por variações térmicas;

- Resistir a degradação ocasionada por influências climáticas, térmicas, químicas e biológicas;

- Resistir ás pressões hidrostáticas, de percolação, coluna d'água do solo, bem como deslocamento ocasionado por perda de aderência;

- Apresentar aderência, flexibilidade e estabilidade físico-mecânica compatíveis com as solicitações previstas nos demais projetos;

- Resistir ao ataque agressão de raízes de plantas ornamentais.

Ainda de acordo com a norma NBR 9575:2010, os sistemas devem resistir a um ou mais esforços expostos atuantes neles, conforme mostra o Quadro 1. Além disso, a norma expõe que a escolha do tipo de sistema de impermeabilização adequado a ser aplicado nas obras de construção civil, deve levar em consideração a solicitação imposta pelo fluido nas partes construtivas que requerem a estanqueidade.

Quadro 1 - Esforços atuantes na impermeabilização.

\begin{tabular}{|l|l|}
\hline Puncionamento & $\begin{array}{l}\text { Ocasionado pelo impacto de objetos que atuam } \\
\text { perpendicularmente ao plano da impermeabilização. }\end{array}$ \\
\hline Fendilhamento & $\begin{array}{l}\text { Ocasionado pelo dobramento ou rigidez excessiva do sistema } \\
\text { impermeabilizante ou pelo impacto de objetos pontuais sobre } \\
\text { qualquer sistema. }\end{array}$ \\
\hline Ruptura por tração & $\begin{array}{l}\text { Ocasionada por esforços tangenciais ao plano de } \\
\text { impermeabilização, devido á ação da frenagem, aceleração de } \\
\text { veículos ou pela movimentação do substrato. }\end{array}$ \\
\hline Desgaste & $\begin{array}{l}\text { Ocasionado pela abrasão devida á ação de movimentos } \\
\text { dinâmicos ou pela ação de intemperismo. }\end{array}$ \\
\hline Descolamento & - Ocasionado por perda de aderência. \\
\hline Esmagamento & $\begin{array}{l}\text { Redução drástica da espessura, ocasionada por } \\
\text { carregamentos ortogonais ao plano de impermeabilização. }\end{array}$ \\
\hline
\end{tabular}

Fonte: (Amaral, 2017).

\subsection{Infiltração de água em construção por capilaridade}

Segundo Manual técnico de impermeabilização (2010), A água existente no solo pode subir pelas paredes até quase 1 metro. Isso faz a pintura descascar, reboco soltar-se e surgir o mofo. Por isso, a alguns anos quando não havia os impermeabilizantes, as edificações eram providas de porões, cuja finalidade principal era a de confinar a umidade proveniente do solo, impedindo-a de 
atingir o interior das habitações. Conforme apresenta as figuras na página seguinte. (Manual técnico. Otto Baumgart ind. e Com. S.A., 2010).

Figura 2 - Sistema de capilaridade no substrato
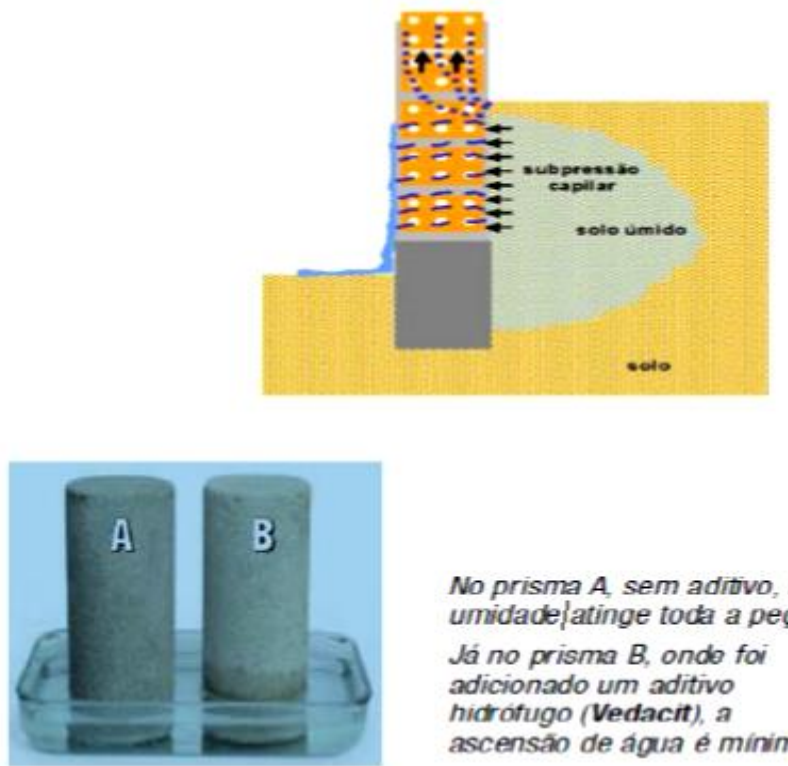

$$
\begin{aligned}
& \text { No prisma A, sem aditivo, a } \\
& \text { umidadejatinge toda a peça. } \\
& \text { Já no prisma B, ondo foi } \\
& \text { adicionado um aditivo } \\
& \text { hidrofugo (Vedacit), a } \\
& \text { ascensáo de agua é minima. }
\end{aligned}
$$

Fonte: (Manual técnico. Otto Baumgart ind. e Com. S.A., 2010).

\subsection{Infiltração de água em construção por Percolação}

Chama-se percolação a passagem de água através de um corpo por transmissão de grão a grão. No caso de alvenaria, a água encharca um grão, que por sua vez vai encharcando outro grão seguinte, até atravessar toda parede. Conforme indicado na figura 3. (Manual técnico. Otto Baumgart ind. e Com. S.A., 2010).

Figura 3 - Sistema de percolação no substrato

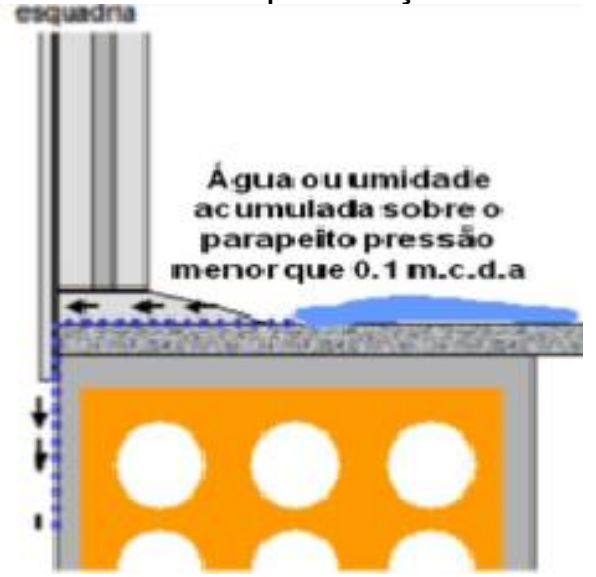

Fonte: (Manual técnico. Otto Baumgart ind. e Com. S.A., 2010). 


\section{FUNDAÇÕES}

As fundações têm como função principal a transmissão de cargas da estrutura para o terreno onde se encontram implantadas, constituindo elementos de muita importância. Elas permanecem em constante contato com a umidade do solo. Embora sejam estruturas que não são expostas às intempéries, assim eleva-se a pertinência da sua impermeabilização, evitando graus de degradação rápida e futuros nas fundações. (Mendes, 2011).

Devido às necessidades das construções de novos espaços urbanos, ao continuo crescimento e grau de exigências da população, evoluíam tanto em altura como na profundidade. Impulsionouse uma maior necessidade de impermeabilização, quanto à preocupação com os elevados níveis freáticos e teor de umidade do terreno, os locais, mais profundas ficam sujeitas a águas permanentes exercendo maior pressão sobre a estrutura. (Mendes, 2011).

De acordo com as normas europeias, são conhecidos dois grandes grupos de materiais em sistemas de impermeabilização: os pré-fabricados e modificados in loco. No quadro abaixo, são apresentadas as membranas (materiais pré-fabricados), existentes em Portugal, geralmente aplicadas em coberturas e fundações. Segundo (Mendes, 2011.p.27).

O Quadro 2, apresenta os diferentes materiais de impermeabilização.

Quadro 2 - Materiais pré-fabricados de impermeabilização

\begin{tabular}{|c|c|c|}
\hline \multirow{3}{*}{$\begin{array}{c}\text { Membranas } \\
\text { com base } \\
\text { em betume }\end{array}$} & \multicolumn{2}{|c|}{ Betumes modificados } \\
\hline & \multicolumn{2}{|c|}{ Betume-polímero de estireno-butadieno-estireno (SBS) } \\
\hline & \multicolumn{2}{|c|}{ Betume-polímero atáctico (APP) } \\
\hline \multirow{15}{*}{$\begin{array}{c}\text { Membranas } \\
\text { com base } \\
\text { em } \\
\text { polímeros } \\
\text { sintéticos }\end{array}$} & \multirow{9}{*}{ Termoplásticos } & Cloreto de polivinilo plastificado (PVC-P) \\
\hline & & Polietileno de alta densidade (PEAD) \\
\hline & & Polietileno de baixa densidade (PEBD) \\
\hline & & Poliolefinas (TPO) \\
\hline & & Polipropileno (PP) \\
\hline & & Polietileno (PE) \\
\hline & & Poliolefina modificada com etileno propileno (EPR) \\
\hline & & Polietileno clorado (PEC) \\
\hline & & Polisobutileno (PIB) \\
\hline & \multirow{2}{*}{$\begin{array}{l}\text { Termoplásticos- } \\
\text { elastómeros }\end{array}$} & Copolimero de etileno/propileno (E/P) \\
\hline & & Polietileno clorosulfonado (CSM) \\
\hline & \multirow{4}{*}{ Elastómeros } & Etileno-propileno-dieno-monómero (EPDM) \\
\hline & & Copolimero isobutileno e de isoprene (Butyl)(IIR) \\
\hline & & Borracha de cloroprene (CR) \\
\hline & & Borracha nitrilica / butadieno (NBR) \\
\hline
\end{tabular}

Fonte: (Mendes, 2011). 
Para caso especifico de impermeabilizações de fundações, os materiais pré-fabricados geralmente utilizados são seguintes:

- Membranas de betumes oxidados e betumes-polímeros APP e SBS;

- Membranas de PEAD, PVC-P, TPO, PP e PE;

- Membranas de EPDM;

- Geocompósitos.

Quanto aos materiais moldados in loco, adequado a este tipo, são indicados os seguintes:

- Emulsões e tintas betuminosas;

- Revestimentos de base cimentícia.

\subsection{Tipos de fundações passiveis de impermeabilização}

\subsubsection{Sapatas isoladas e Corridas}

As fundações passivas de ser impermeabilizadas são: (sapatas corridas ou vigas), radier (face superior ou inferior) e estacas (topo ou maciço de encabeçamento). (Amaral, 2017). Conforme mostram as figuras 4 e 5 abaixo indicado.

Figura 4 - Sapata Impermeabilizada

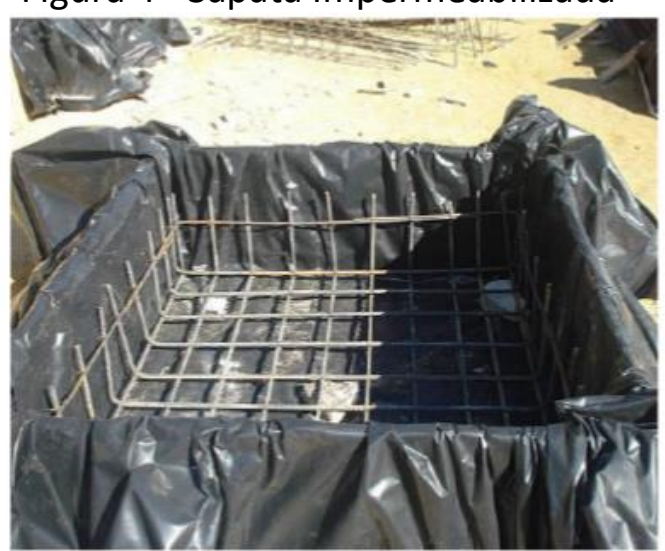

Figura 5 -Sapata Isolada

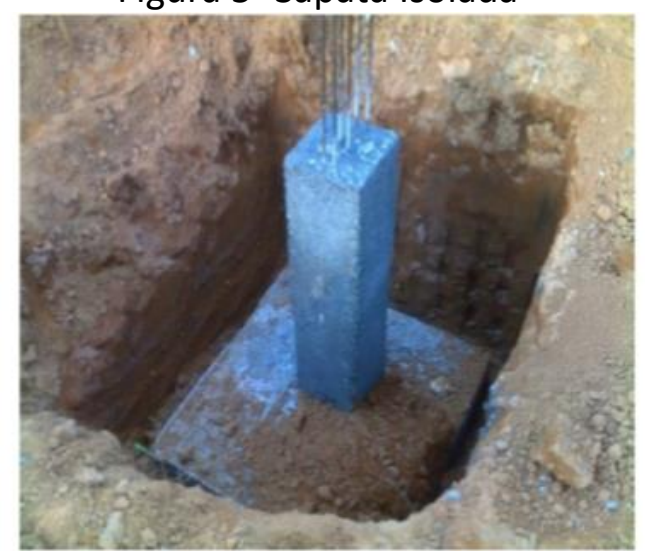

Fonte: (Mendes, 2011).

O instituto brasileiro de impermeabilização, IBI - (2017) aponta a umidade ascendente ou por capilaridade como problemas comuns na estrutura. A solução que oferece são os sistemas rígidos, como argamassa polimérica, e sistemas flexíveis, como membranas de asfalto modificado com polímeros e solução.

De acordo com as características das novas tecnologias que serão aprendidos nos próximos capítulos, as mantas pré-aplicadas (PEAD), são ideais para esse tipo de estrutura. $\mathrm{O}$ sistema consiste na aplicação de uma manta que dispensa a proteção mecânica, ela é fabricada por múltiplas lâminas de polietileno de alta densidade, elevados índices de durabilidade e resistência. (Amaral, 2017). 
Esse sistema é bastante diferenciado, pois além de possibilitar a impermeabilização do local, possibilita a proteção da estrutura de ambientes enterrados.

Mendes, (2011), ressalva que este tipo de membranas tem a dupla funcionalidade de drenagem e de impermeabilização, como forma de substituir Concreto magro, auxiliando também a drenagem do local. A vida útil estimada entre 200 e 300 anos, de acordo com diferentes autores e condições de ensaios. Quando se encontram expostas, a vida útil estimada diminui a partir de 50 anos. Mas quando se trata de um solo constantemente úmido, a membrana resiste entre 120 e 150 anos. A figura 6 mostra a manta PEAD.

Figura 6 - Membrana termoplástica PEAD

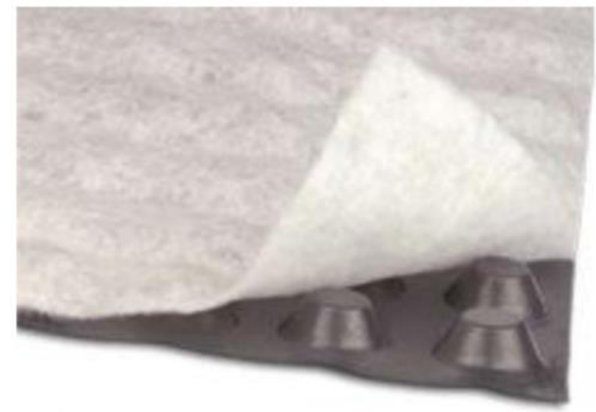

Fonte: (Mendes, 2011).

Dentro do grupo das sapatas, ao impermeabilizar as sapatas corridas, conforme mostra as figuras abaixo, que correspondem a um conjunto de sapatas unidas continua, segundo um determinado alinhamento, que acompanha o alinhamento das paredes do edifício, transmitindo a carga por metro.

Figura 7 - Sapata corrida Figura 8 - Impermeabilização da sapata
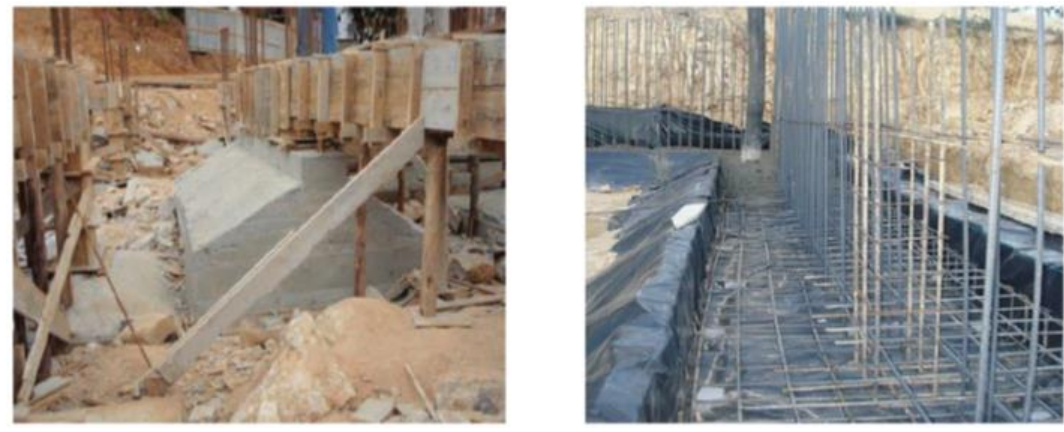

Fonte: (Mendes, 2011)

\subsubsection{Estacas}

A impermeabilização de fundações profundas é um pouco mais complexa do que a impermeabilização de fundações diretas. Isto é devido a impossibilidade de impermeabilizar toda a estaca (fuste da estaca). Existem dois casos possíveis de impermeabilização das estacas, por isso opta-se por impermeabilizar a cabeça de estaca simples ou maciço de pescoço. (FREITAS,2013). 
A figura 9, mostra que para uma boa impermeabilização, a cabeça da estaca deve estar devidamente limpa e livre de impurezas para que o produto impermeabilizante possa atingir de forma uniforme a superfície. (MENDES, 2011).

Figura 9 - Tratamento da cabeça de estaca com escova de aço.

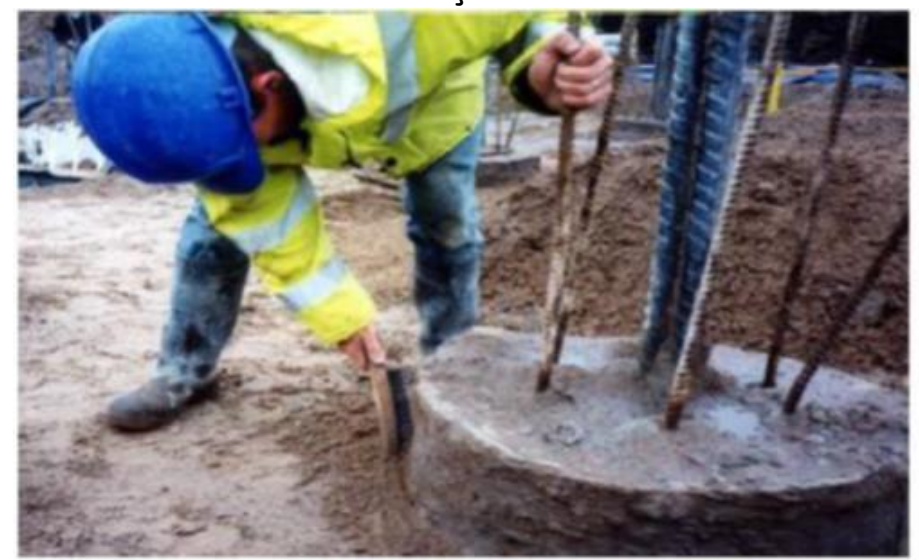

Fonte: (Mendes, 2011)

É inconveniente impermeabilizar o topo da estaca e depois não proteger a superfície inferior da laje, neste caso a impermeabilização das estacas só fará sentido se impermeabilizar a superfície da laje também. Assim a membrana de impermeabilização deve cobrir toda superfície horizontal e a superfície lateral da estaca, com utilização de argamassas aditivadas, visto que é o único produto com capacidade de suportar as cargas transmitidas ao elemento. Devido a sua flexibilidade e capacidade de impermeabilização, a membrana, mais aconselhável será membrana de PVC-P, FPO e EPDM ou geocompósitos bentoníticos, podem ser aplicados em sistema independente, aderido ou por fixação mecânica. A adesão deste gênero de membranas executa-se com solvente de colagem ou recorrendo a membrana autoadesivas. (BASTOS, 2014).

Em volta da estaca e no interior da membrana de impermeabilização é aplicado um waterstop em forma de um arco, formando uma barreira estanque. Conforme indicado na figura 11, na página seguinte.

Figura 10 - Impermeabilização de estacas com a membrana de PVC-P.
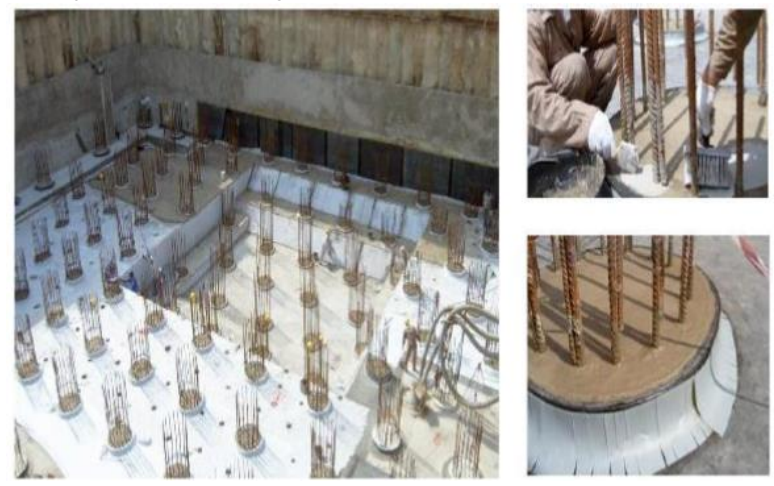

Fonte: Bastos (2014). 
Figura 11 - Esquema de impermeabilização de estacas

Argamassa aditivada

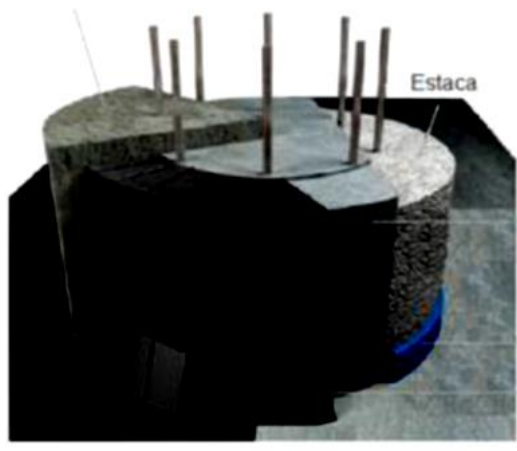

Revestimento

cimenticio

Waterstop

Membrana

impermeável

Fonte: (Mendes, 2011).

Outra solução de impermeabilização de fundações profundas é a impermeabilização de todo o maciço de encabeçamento. Como se observa a figura 12. A cabeça da estaca é impermeabilizada de forma idêntica à descrita anteriormente e o maciço é impermeabilizado como se tratasse de uma sapata, com o uso de um geocompósito bentonítico. Mendes (2011).

Figura 12 - Impermeabilização com Geocompósitos dos maciços de pescoço

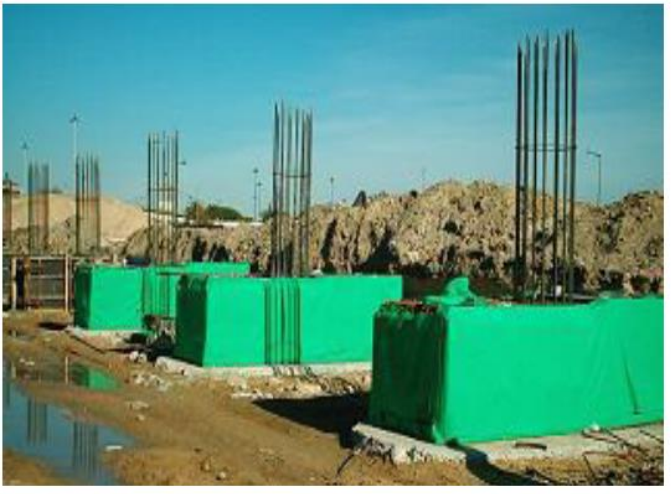

Fonte: (Mendes, 2011)

\subsubsection{Radier}

É idêntico a uma laje em planta extensa. A sua espessura é comparada com uma laje de grandes dimensões. É uma laje de concreto armado que resiste à flexão em resultado do seu contato com o terreno e da reação deste as cargas provenientes dos pilares diferentemente carregados. A sua utilização é frequente, quando existe carregamentos elevados em todo o radier. São aplicados em terrenos com características mecânicas elevadas, apenas com grande profundidade ou em terrenos superficiais fracos, mas passíveis de receber cargas. Como mostra a figura 13. (MENDES, 2011).

Antes da sua execução o terreno deve estar bem compactado com auxílio de diversos equipamentos de compactação. Depois prosseguir com processo de aplicação de forma, armação e finalizando com a forma. Este tipo de fundação é bastante útil para situações em que os níveis freáticos se encontrem próximo ou acima do piso térreo. E tem uma grande vantagem, no sentido 
em que constitui uma plataforma de trabalho para serviços posteriores, obrigando, no entanto à execução precoce de todas as especialidades enterradas (instalações sanitárias), etc. Como indicado a figura 14, na página seguinte. (Freitas, 2013).

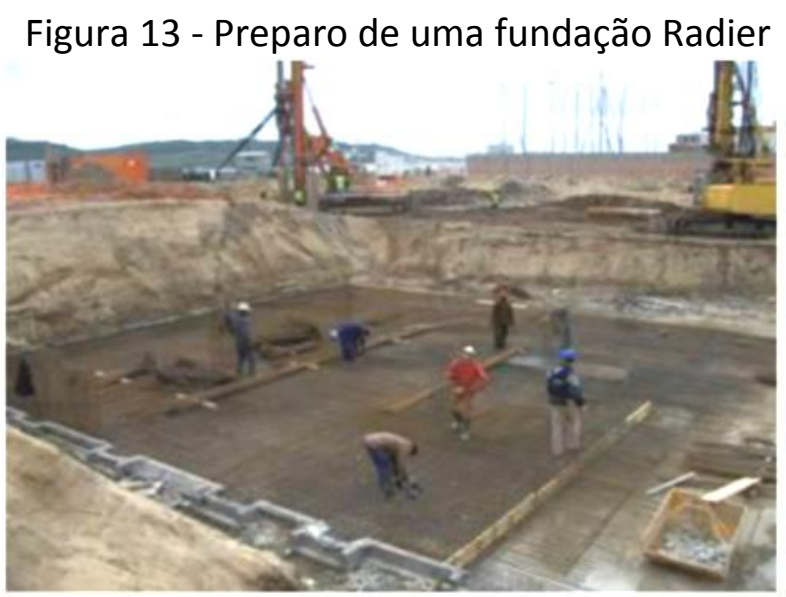

Fonte: (Mendes, 2011).

Figura 14 - Sistema de impermeabilização de um radier

Fonte: (Freitas, 2013).

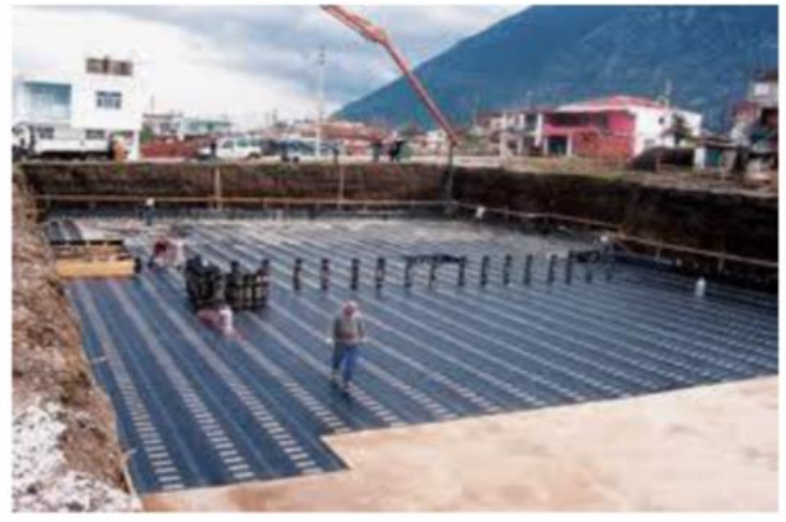

4.1.4 Subsolos, Baldrames e poços de elevador

Para impermeabilizar um subsolo de forma segura, de modo que não venham a ocorrer problemas ao longo dos anos, devemos formar um invólucro impermeável que envolva toda a estrutura submersa pelo lado de fora, isto é, pelo lado de onde vem à água (ninguém veste uma capa por baixo do paletó). No entanto é comum a impermeabilização pelo lado interno dos subsolos, simplesmente por não se ter pensado no problema, anteriormente, durante o projeto. (RIPPER, 1995).

Desta forma, existem dois casos a se estudar para definirmos o tipo de impermeabilização a ser aplicada. (Cunha, 1997). 
A impermeabilização deve envolver os alicerces ou vigas de baldrame, descendo lateralmente no mínimo $15 \mathrm{~cm}$. A execução, mais simples é de uma camada de $1,5 \mathrm{~cm}$ de espessura de argamassa de cimento e areia media, lavada, 1:3, com aditivo impermeabilizante. Conforme figuras 15 e 16.

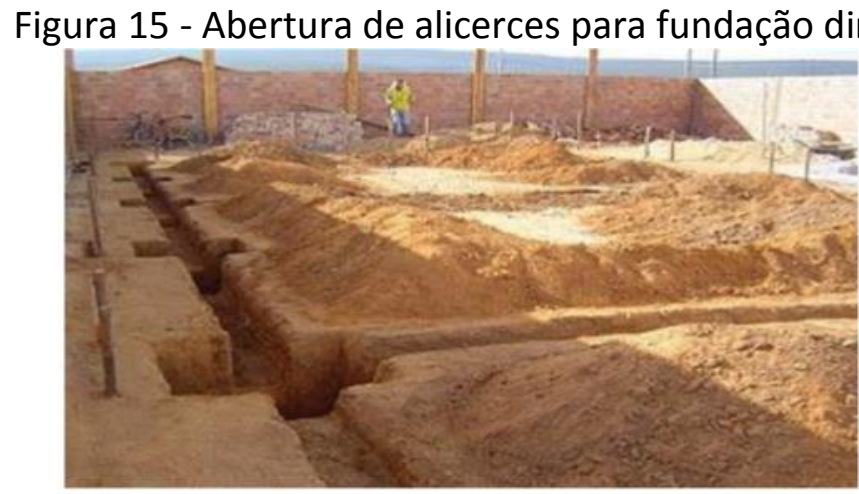

Fonte: (Mendes, 2011).

Figura 16 - Impermeabilização de baldrames com emulsões asfálticas

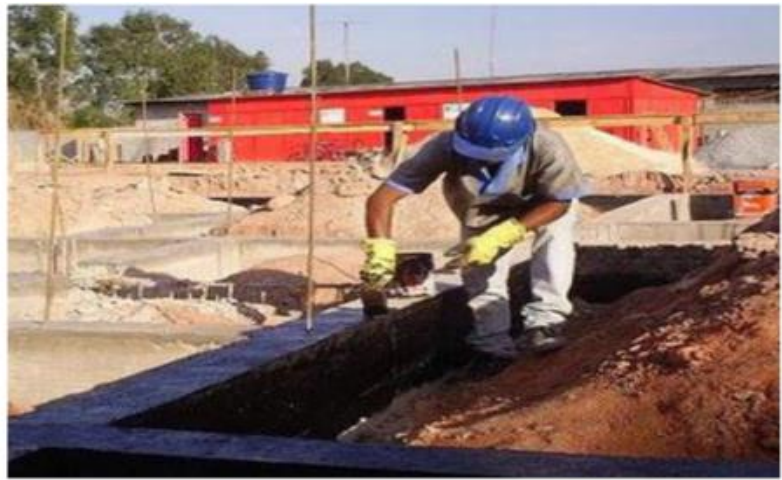

Fonte: (Freitas Jr, 2013).

\subsection{Sistemas de Vedação e Tamponamento}

O sistema de tamponamento entende-se como processos que fazem cessar a penetração de fluxo da água através das paredes do subsolo. Quanto a sua estanqueidade, poderão ser de vários tipos, dependendo da infiltração verificada.

- $\quad$ Sistemas superficiais - Segundo CUNHA (2005), para tamponar os casos de infiltração de fluxo de água com baixa pressão, o revestimento impermeável, rígido, sendo empregados cimentos especiais de cura rápida, do tipo STOP-MORTER, ou argamassas impermeabilizantes

- $\quad$ Sistemas de Injeção - Para tamponar e vedar infiltração do muita ou media pressão d'água, existem dois (2) sistemas:

- $\quad$ Sistema Rígido - Consiste em injeções de resinas sintéticas reativas, de tipo epóxi, aplicadas no local da infiltração, não sendo recomendados quando o elemento 
construtivo apresentar-se decomposto ou em desagregação, pois não oferecerá condições de aderência e reação adequada da resina.

- $\quad$ Sistema Elástico - Poderá ser adotado em qualquer tipo de infiltração, sendo econômica e tecnicamente, recomendado para infiltrações dos tipos 5.2 e 5.3. Essa técnica de injeção baseia -se no lençol freático de produtos que se transformarão numa pasta elástica e pegajosa, promovendo o tamponamento da infiltração de fora para dentro, garantindo a estanqueidade em paredes de concreto, na rocha ou na terra. (Cunha, 2005).

TEXTASA 500/TEXSA 100 (líquidos compostos de polímeros sintéticos de grande elasticidade associados a betumes) são produtos desenvolvidos pela TEXSA BRASILEIRO, para sistema de injeção profundas, que tamponam os pontos de penetração da água, atravessando, na maioria das vezes, a parede a ser vedada e injetando sob pressão. As partículas coloidais da massa em formação ancoram e penetram nos veios de infiltração, entupindo-se ou tamponando-os, com absoluta segurança. Segundo (Cunha, 2005).

\subsection{Serviços de impermeabilização}

Sistema de impermeabilização não desempenha seu papel de maneira satisfatória sem levar em consideração seus subsistemas, matérias e suas relações.

\subsubsection{Procedimentos preliminares}

- Preparo e regularização das superfícies horizontal/vertical (Caimento)

A superfície deve estar desimpedida e livre para o trabalho de impermeabilização, corrigindo eventuais falhas de concretagem, eliminando depressões e pontas nocivas ao sistema, como mostram as imagens da figura 17.

A superfície deve estar seca e limpa, para possibilitar a perfeita aderência da impermeabilização.

Figura 17 - Superfície regularizada
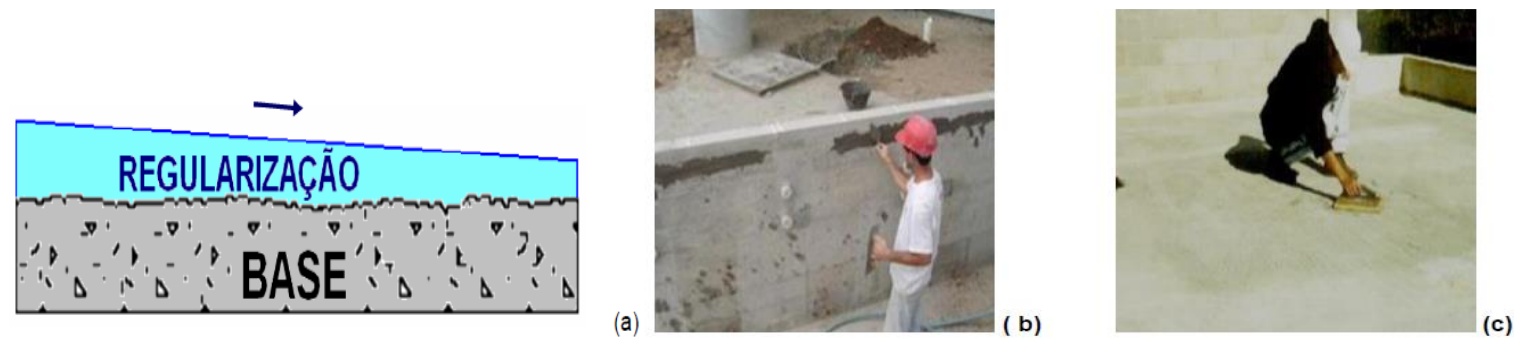

Fonte: Freitas (2013). 
Caimento deve ser de no mínimo $1 \%$ em áreas externas em direção aos coletores de água, segundo a norma NBR 9574/2010, e para locais de difícil acesso recomenda-se 3\% de caimento, conforme indicado as figuras 18 e 19.

Figura 18 - Caimento da regularização (1\%)

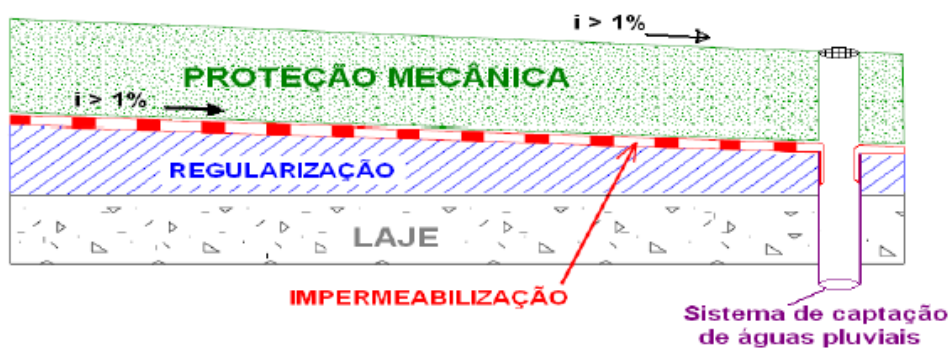

Fonte: (Freitas, 2013).

Figura 19 - Caimento da regularização (3\%)

Fonte: (Soares, 2014).

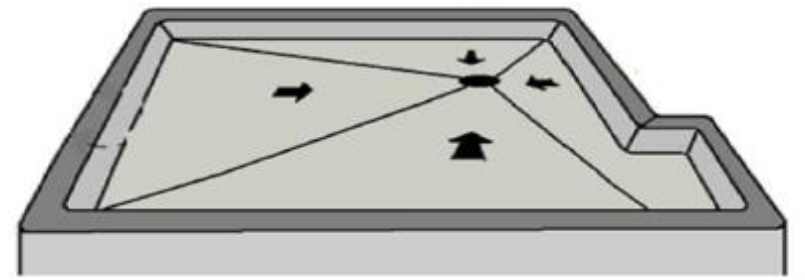

\subsubsection{Rodapés}

Muitas das vezes é esquecido durante a impermeabilização, pois ele constitui um ponto crítico já que a sua execução pode comprometer o sistema de impermeabilização. A camada impermeável deve subir $20 \mathrm{~cm}$ acima do nível do piso acabado ou $10 \mathrm{~cm}$ do nível máximo que a água pode respingar para outro lado. (NBR 9575:2010). Mas outros autores afirmam que para boxes, a uma altura de $40 \mathrm{~cm}$, de acordo com a figura 20 .

Figura 20 - Aplicação de impermeabilização no rodapé
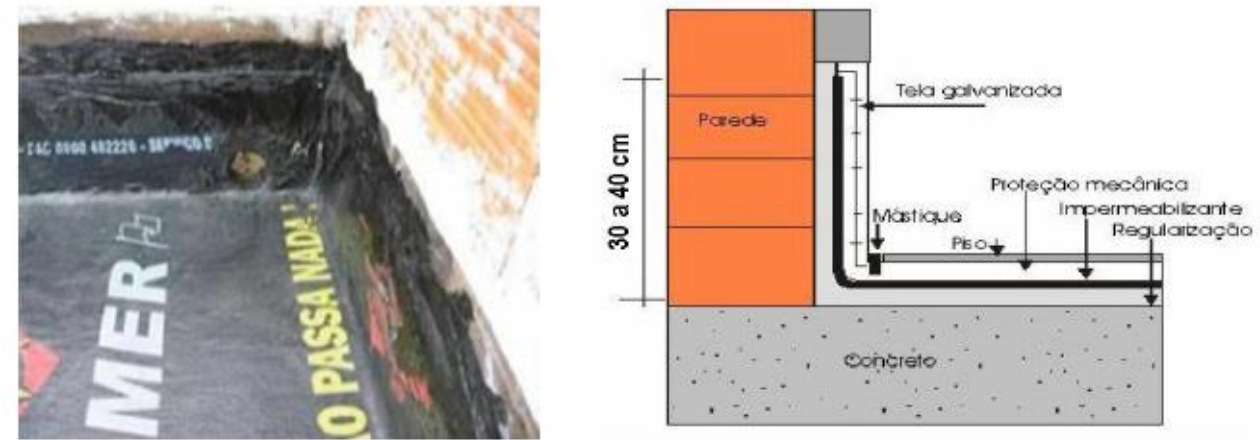

Fonte: (Freitas, 2013)

Lembrando que os cantos e arestas vivas devem ser arredondadas com raios compatíveis com o sistema de impermeabilização, a fim de permitir um ajustamento continua dos sistemas, 
evitando a dobragem em ângulo (AMARAL, 20117). A figura 21 mostra que o arredondamento dos vértices deve ser de $8 \mathrm{~cm}$ de raio, e a cura mínima da argamassa de regularização deverá ser de 48 horas.

Figura 21 - arredondamentos de cantos
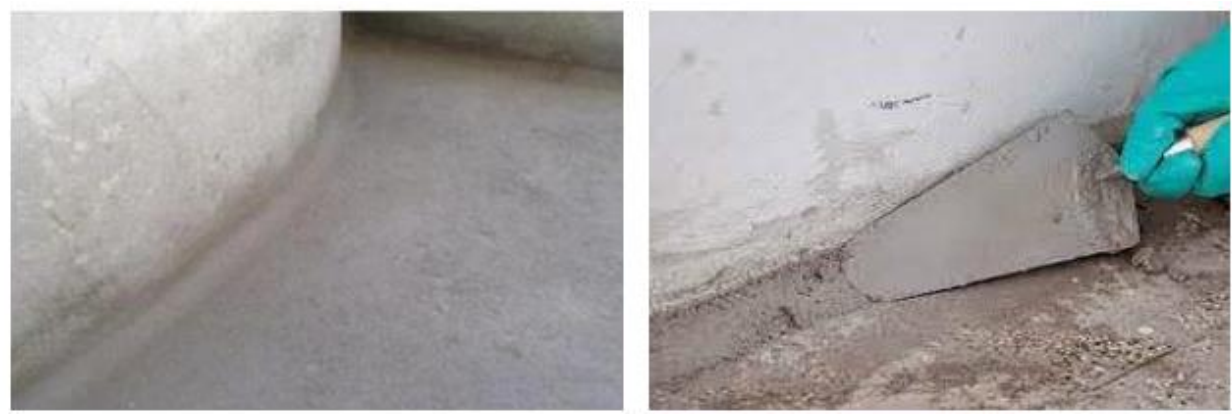

Fonte: (Silva, 2014).

A norma NBR 9575:2010, ressalva que a argamassa deve ser preparada com areia lavada, cimento e água limpa, em tempos secos e quentes. Nas áreas a serem impermeabilizadas depois da regularização e esperar o tempo de secagem, que depende do fabricante do impermeabilizante a ser colocado.

\subsubsection{Tratamento de Ralos}

De acordo a norma NBR 9575:2010, os coletores devem ter diâmetro que garanta a manutenção da seção nominal dos tubos prevista no projeto hidráulico após a execução da impermeabilização, sendo o diâmetro nominal mínimo de $75 \mathrm{~mm}$. Nos ralos deverá haver um rebaixamento de $3 \mathrm{~cm}$ de profundidade de $40 \times 40 \mathrm{~cm}$ com bordas chanfradas para que haja nivelamento de toda a impermeabilização, após a colocação dos reforços previstos. (Freitas Jr, 2013), conforme indicado na figura 22.

Figura 22 - Ralo com rebaixamento na regularização

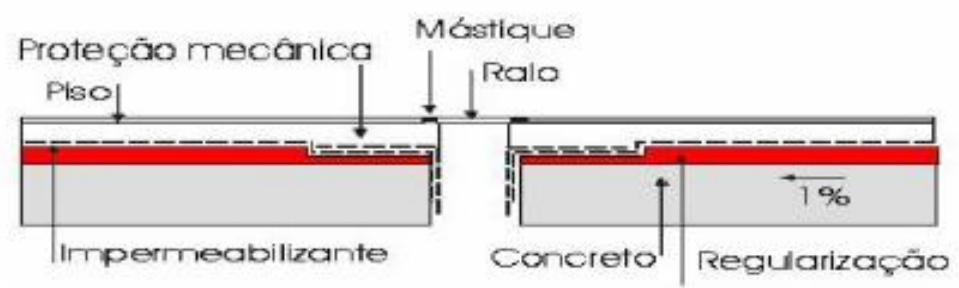

Fonte: (Freitas, 2013)

\subsubsection{Junta de dilatação}

As juntas de dilatação podem ter configurações diferentes, variando de acordo com o fabricante que produz. As dimensões dependem da pressão de água e da eficiência pretendida, 
sendo que sua espessura é geralmente de $3 \mathrm{~mm}$. (Mendes, 2011), Conforme apresenta a figura 23 abaixo.

Figura 23 - Junta de dilatação em PVC

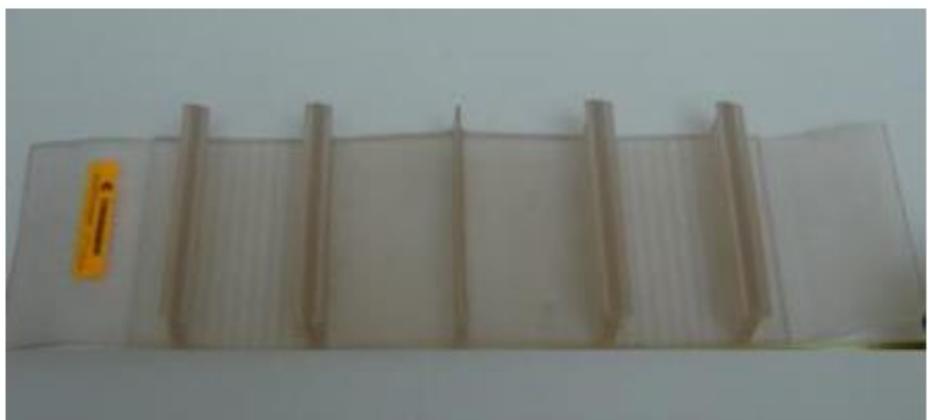

Fonte: (Mendes, 2011)

As ligações de topo a topo são feitas através de um pequeno aparelho que permite um corte reto nos topos, de forma a uni-los corretamente. Em seguida, são aquecidos com uma lâmina quente.

Nas juntas horizontais utiliza-se um limitador de profundidade (comum usar o poliestireno expandido, mais comumente chamado de isopor), antes da execução da impermeabilização com manta, fazendo o dobro até o limitador e retomando a superfície. O mastique, material flexível, é usado para possibilitar a movimentação da estrutura e impedir que a manta se dobre. Outras camadas de manta são recomendadas para proteger o mastique e reforçar a impermeabilização. (Amaral, 2017). Conforme mostra a figura 24.

Figura 24 - Detalhe de Impermeabilização de junta de dilatação horizontal

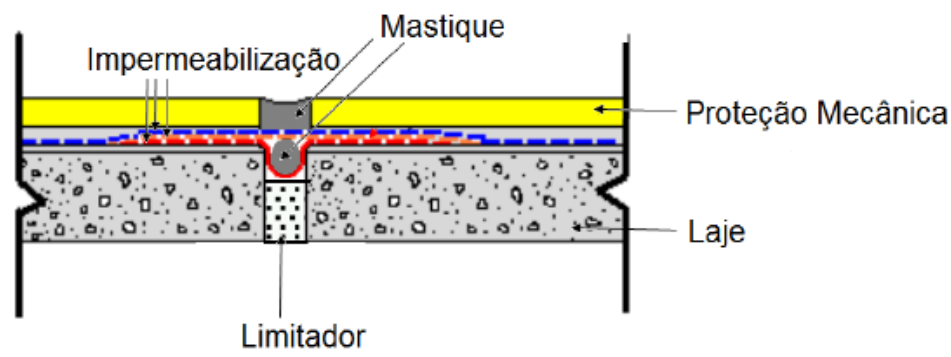

Fonte: (Freitas, 2013).

\subsubsection{Proteção mecânica}

A proteção mecânica é uma camada que tem a função de proteger a camada impermeabilizante, absorvendo e dissipando os esforços, sejam estáticos ou dinâmicos, que atuam na mesma. 
A proteção é executada imediatamente após a liberação do ensaio hidráulico. Este deve ser executado após a cura da camada impermeável e deve durar, no mínimo 72 horas, a fim de se detectar eventuais falhas. (NBR 9575:2010) (figuras 25 e 26).

Figura 25 - Desenho esquemático de acabamento de paredes Verticais

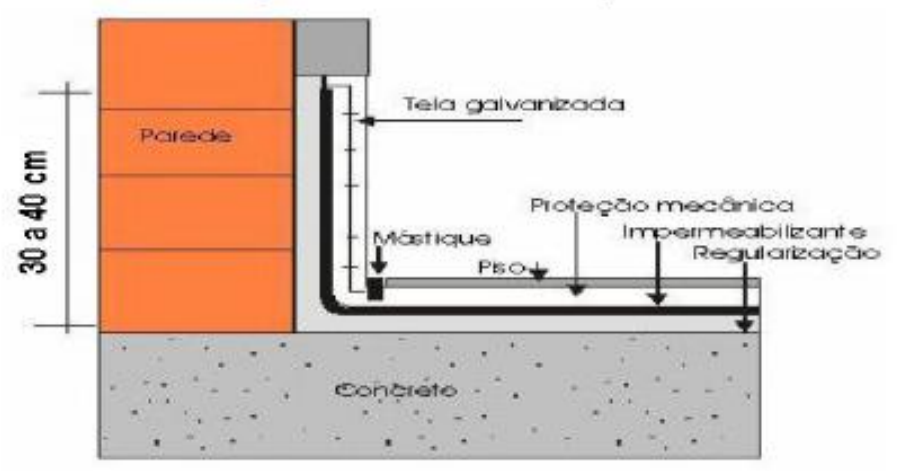

Fonte: (Freitas, 2013)

Figura 26 - Acabamento de paredes Verticais
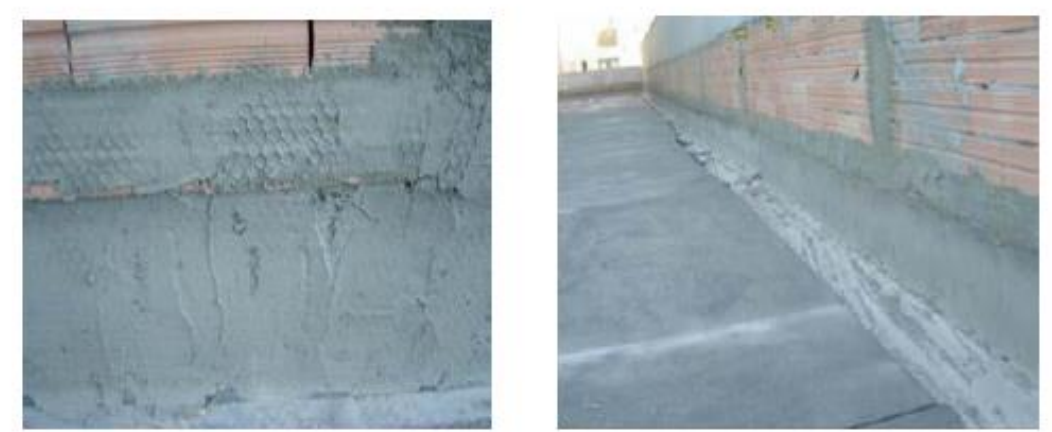

Fonte: (Freitas, 2013)

\section{CONSIDERAÇÕES FINAIS}

Este trabalho tratou de fundações passiveis de serem impermeabilizadas como: sapatas (isoladas, corridas ou vigas) e estacas (topo ou maciço de encabeçamento). Desta forma, os projetos arquitetônicos são concebidos sempre visando ao máximo o aproveitamento destas áreas. Verificou-se que os pavimentos inferiores foram bastante afetados por estarem expostos a grande concentrações de água da chuva e influência do lençol freático. Neste trabalho também referenciouse várias anomalias decorrentes em fundações e os vários materiais que protegem as estruturas.

\section{REFERÊNCIAS}

ASSOCIAÇÃO BRASILEIRA DE NORMAS TÉCNICAS. NBR 9474: Execução de impermeabilização procedimento. Rio de Janeiro, 2008. 
ASSOCIAÇÃO BRASILEIRA DE NORMAS TÉCNICAS. NBR 9475: Execução de impermeabilização: seleção e projeto - procedimento. Rio de Janeiro, 2003.

ASSOCIAÇÃO BRASILEIRA DE NORMAS TÉCNICAS. NBR 9575: Impermeabilização seleção e projeto. Rio de Janeiro, 2010.

ASSOCIAÇÃO DAS EMPRESAS DE IMPERMEABILIZAÇÃO DO ESTADO DO RIO DE JANEIRO. História da impermeabilização. Disponível em: http://aei.Org.br/ história-da-impermeabilização/. Acessado em: setembro 2017.

AMARAL, Tahita Chaves Abreu. Sistemas de Impermeabilização - Características e Seleção. Rio de Janeiro: Cefet/RJ, 2017.

BASTOS, Luís Filipe Barros Fernandes. Análise Comparativa de Sistemas de Impermeabilização. Dissertação de Mestrado em Engenharia Civil na Especialidade de Construções, Universidade de Coimbra. 2014.

CUNHA, Aimar Gonçalves, Ronaldo Ribeiro. Impermeabilização e Isolamento Térmico: Materiais e Especificações. 1ạ edição, São Paulo, 1997.

CUNHA, Aimar Gonçalves, Neumann, Walter. Manual de Impermeabilização e Isolamento Térmico. 5 a edição, São Paulo, 1997.

FREITAS, José A Jr. Impermeabilização. Disponível em: http://docplayer.com.br /434843Impermeabilizacao-construcao-civil-ii-tc-025-prof-jose-de-almendra-freitas-jr-freitasjose-terracom-br.html. Acessado em: outubro 2017.

LONZETTI. Impermeabilizações em subsolos de edificações residenciais e comerciais. Porto Alegre: UFRGS, 2010.

Manual Técnico. Impermeabilização em estruturas, 4. ed. - Otto Baumgart ind. e Com. S.A. (2010).

MENDES, Paula Alexandra da S. Impermeabilizações de fundações de edifícios e estruturas especiais. Lisboa: UTS 2011.

RIIPPER, Ernesto. Manual Prático de Materiais de Construção. 1a edição, São Paulo: pini, 1995.

RL IMPERMEABILIZAÇÃO DESENVOLVIMENTO: MDS Brasil 2014. História da Impermeabilização. Disponível em: http://www.rlimpermeabilizacao.com.br/?rl=impermeabilizacao. Acessado em 28 de setembro de 2017.

SILVA, Carlos Eduardo. Impermeabilização de banheiro com argamassa polimérica. Disponível em: http://ceosolucoesparaconstrucao.blogspot.com.br/2014/ 05/impermeabilizacao-de-banheirocom.html. Acessado em: julho, 2016.

SOARES, Felipe F. A importância do projeto de impermeabilização em obras de construção civil. Rio de Janeiro: EdUFRJ, 2014. 